\title{
DESLOCAMENTO DE ARTISTAS NEGRAS(OS) NO INÍCIO DO SÉCULO XX: INVÓLUCRO, DESOBEDIÊNCIA E OCUPAÇÃO
}

\author{
DISPLACEMENT OF BLACK ARTISTS \\ IN THE BEGINNING OF THE 20 ${ }^{T H}$ CENTURY: \\ COVERING, DISOBEDIENCE, AND OCCUPATION
}

DESPLAZAMIENTO DE ARTISTAS

NEGRAS(OS) EN LOS INICIOS DEL SIGLOXX: ENVOLTURA, DESOBEDIENCIA Y OCUPACIÓN

\section{Deise Santos de Brito}

Deise Santos de Brito

Artista da dança, do teatro e educadora. Mestra em Artes pela Escola de Comunicações e Artes da Universidade de São Paulo e doutoranda em Artes pelo Instituto de Artes da Universidade Estadual Paulista "Júlio de Mesquita Filho". Atualmente é pesquisadora visitante na University of Louisville, Estados Unidos. 


\section{Resumo}

Este artigo apresenta algumas estratégias de articulação construídas a partir do deslocamento de artistas negras(os) do início do século $X X$, a fim de fortalecer o contexto referente a suas gerações sucessoras. Referências teóricas decoloniais como Walter Mignolo, Lélia Gonzalez e Frantz Fanon dialogam com algumas referências da historiografia teatral, como Roberto Ruiz e Orlando de Barros, para pensar esses processos. O objetivo deste texto é reunir algumas informações que evidencie alguns encontros entre artistas negras e negros afim de colaborar na potencialização de uma historiografia cada vez mais crescente que vem abordando a presença da(o) artista negra(o) na cena brasileira.

Palavras-chave: Teatro de Revista, Decolonial, Deslocamento, Invólucro.

\section{Abstract}

This article presents strategies of articulation based on the displacement of black artists in the beginning of the $20^{\text {th }}$ century to emphasize the context regarding later generations. Theoretical and decolonial references such as Walter Mignolo, Lélia Gonzalez, and Frantz Fanon dialogue with some theatre historiography references, such as Roberto Ruiz and Orlando de Barros, to think about this processes. The aim of this text is to gather information that evidence a few meetings between female and male black artists in order to collaborate in the enhancement of an ever-growing historiography that has been approaching the presence of the black artist in the Brazilian scene.

Keywords: Revue Theater, Decolonial, Displacement, Covering.

\section{Resumen}

El objetivo de este artículo es presentar algunas estrategias de articulación construidas a partir de los desplazamientos de artistas negras/os en los inicios del siglo XX para fortalecer los contextos referentes a las conexiones entre artistas negras/os contemporáneos. Referencias teóricas decoloniales como las de Walter Mignolo, Lélia Gonzalez y Frantz Fanon dialogan con algunas referencias de la historiografía teatral como Roberto Ruiz y Orlando de Barros para pensar estos procesos. El objetivo de este texto es reunir algunas informaciones que evidencien algunos encuentros entre artistas negras y negros a fin de colaborar en la potenciación de una historiografía cada vez más creciente que viene abordando la presencia de la/el artista negra/o en la escena brasileña.

Palabras clave: Teatro de Revista, Decolonial, Desplazamiento, Envoltura. 


\section{A importância de se deslocar para o passado}

Antes de tudo é interessante pontuar que este artigo tem pretensões de pensar artistas negras e negros mais a partir de uma epistemologia decolonial do que pós-colonial. Tal escolha é por verificar que as referências e os estudiosos decolonialistas tencionam o projeto colonial de forma mais assertiva, que converge com o anseio relacionado ao propósito deste trabalho: identificar contraprojetos coloniais do ponto de vista de narrativas referentes à pessoa negra no campo das artes na América Latina. Mas não significa que perspectivas de pensamentos pós-colonialistas não apareçam ao longo do texto, tendo em vista que as duas correntes teóricas se encontram em alguns momentos (BALLESTRIN, 2013) ${ }^{1}$.

Para refletir acerca dos processos e práticas artísticas construídas a partir de diálogos com culturas de matriz africana, é necessário acompanhar os movimentos das pessoas negras que cultivaram esses contextos, pois são elas que criam e recriam as heterogeneidades imersas na negritude, a qual não se desvincula das culturas negro-diaspóricas.

As referências são mestres, griots, músicos, artistas cômicos, dançarinas, coristas, cenógrafas, ensaiadores que se deslocaram por diversos espaços fazendo arte e articulando saberes. Com o corpo em trânsito, elas e eles inspiram de forma direta e indireta artistas contemporâneos, propondo um exercício de desobediência e reestruturação de práticas dentro de uma estrutura organizada por cânones coloniais.

No Rio de Janeiro, sobretudo localizado em circuitos periféricos, a figura da(o) artista negra(o) sempre foi presente, seja declamando textos, dançando ou apresentando-se em shows de variedades, como aponta Gomes (2004). Daí a necessidade de nos deslocarmos para outras narrativas que

1. Stuart Hall (jamaicano) e Paul Gilroy (inglês), teóricos considerados pós-coloniais, realizaram pesquisas significativas para pensar o local da cultura e da diáspora negra pautados em perspectivas que contestam as fixações binárias e os essencialismos. Já os debates decolonialistas, apesar de aproveitarem alguns elementos dos estudos pós-coloniais, reivindicam um campo de enunciação a partir da realidade latino-americana, buscando uma categorização crítica do ocidentalismo. Uma das vozes pioneiras desse movimento é o argentino Walter Mignolo. Tanto um campo como o outro tem Frantz Fanon como referência-chave para pensar a relação colonizador-colonizado, contudo a usam com diferentes abordagens e objetivos. Ver o texto "América Latina e o giro decolonial', de Luciana Ballestrin (2013). 
não necessariamente comportam a legitimação da história hegemônica, para que outras formas de articulação negra-diaspórica venham ao nosso encontro, a partir de suas próprias lógicas.

\section{Invólucro e ocupação}

Araci Cortes. Esta foi um dos principais destaques do teatro de revista nas décadas de 1920 e 1930, iniciando sua carreira em 1921 no Democrata Circo, o mesmo local onde atuava o palhaço negro Benjamim de Oliveira, importante na construção do circo-teatro no Brasil. É interessante pontuar que o conhecimento da existência de Araci Cortes foi possível através do processo investigativo relacionado ao trabalho do ator Grande Otelo no teatro de revista brasileiro (BRITO, 2011). A partir dos trânsitos e deslocamentos desse ator nos diferentes âmbitos artísticos, foi identificado que Otelo nos anos iniciais de sua carreira teve contato com outras(os) artistas negras e negros. Não é por acaso que ele participa da segunda fase da Companhia Negra de Revistas (BARROS, 2005).

Araci Cortes era uma cantora e atriz que morava no Catumbi, um bairro na cidade do Rio de Janeiro. Sua residência era próxima à casa da família de Alfredo Rocha Viana Júnior, o músico Pixinguinha. As famílias de Araci e Pixinguinha tinham uma proximidade relevante. $O$ pai dele, seu Alfredo, organizava rodas de choro em sua casa, que ficava repleta de amigos como Carlos Espíndola, pai de Araci Cortes:

Seu Alfredo tinha muitos amigos e todos fazendo questão de puxar o seu sonzinho. Conversa vai, conversa vem, o conjunto já estava tocando: o velho Alfredão, Irineu de Almeida, o Candinho do trombone e até os "garotos": china no violão e no cavaquinho, Henrique no violão e na flauta, e Léo no oficiclide. E claro duas meninas no meio, tentando acompanhar com o corpo o ritmo buliçoso, Dalva e Zilda, que as outras estavam muito ocupadas em ajudar no serviço de casa, para atender aquela gente toda. (RUIZ, 1984, p. 14)

A narrativa que Roberto Ruiz nos apresenta, baseada no próprio depoimento de Araci Cortes, indica que as rodas de choro eram momentos de encontros e trocas, microdeslocamentos corporais em que o som, a síncopa e 
a rítmica diaspórica negra ia se inscrevendo no corpo da geração mais jovem, ao mesmo tempo que era reatualizada por ela. O deslocamento é algo inerente à pessoa. Ele não só implica a movimentação para trás, para frente, para as laterais ou para todas essas direções simultaneamente, mas implica também a mudança. E esta, muitas vezes, acontece no campo simbólico, onde significações ancestrais são reestruturadas e provocadas por seus protagonistas, na medida em que as escrituras acontecem no corpo. Zilda era o nome verdadeiro da Araci Cortes, e Dalva era sua irmã. Aprendendo e fazendo, entrelaçada a um território familiar onde práticas negras urbanas eram cultivadas, a artista, com divertimento, apreendia as cosmogonias corporais contidas nas rodas de choro e escrevia nessas mesmas fundamentações como ela enxergava a experiência. Essas vivências seriam constantemente revisitadas e remodeladas por ela futuramente nos palcos do Teatro de Revista. Pixinguinha, ciente de que observar os mais experientes era uma premissa ancestral para aprender naquele ciclo, se deslocava aguardando:

Pixinguinha, o mais novo, esperando vez... E Carlos Espíndola, com a sua flauta presente. As sementes estavam lançadas. lam ser artistas. A música entranhava-se neles, como um vírus, dominando pensamentos e ações. (RUIZ, 1984, p. 14)

Em outro ângulo, outro significado atribuído a deslocar é o desconjuntar ou desarticular. Por exemplo: quando alguém acidentalmente desloca o ombro, esse deslocar gera dor e transtornos, em pequenas ou grandes proporções. O corpo precisa realocar esse membro para restaurá-lo, e essa restauração do osso também causa dor. O ombro, após recolocado, precisa de invólucro por algum tempo até iniciar as sessões de fisioterapia.

A partir disso, deslocar tem outra significação. A mudança aqui vem acompanhada de trauma. Tanto Araci Cortes, Grande Otelo ou Pixinguinha apresentam especificidades e subjetividades, mas existe um passado comum entre eles que é necessário ressaltar. Seus ancestrais viveram os macrodeslocamentos forçados que constituíram a diáspora negra nas Américas sob os alicerces da dominação colonial. Esses deslocamentos desarticularam comunidades das partes Central e Ocidental do continente Africano para o Americano a partir do século $\mathrm{XVI}$, desconjuntaram estruturas de existência 
e traumatizaram pessoas. Essas mesmas pessoas, por diversos caminhos, retornaram simbolicamente ao seu lugar de origem para que suas corporeidades fossem reestruturadas. O samba, o choro, o lundu, o maxixe, entre outras expressões musicais, são cultivados também por esses contextos, visto que negras e negros vivem uma experiência de retorno ao participarem da construção dessas manifestações culturais, revivendo no corpo compassos sincopados e matrizes de movimentos que problematizam um contexto corporal ocidentalizado na medida em que o desobedecem.

O trauma e a necessidade de realocação simbólica, numa situação forçada de mudança de lugar, não paralisou no momento em que o tráfico de pessoas africanas começou a ser proibido no século XIX; pelo contrário, permanecem nos corpos negros contemporâneos, agentes e regentes das diásporas. Não é à toa que o termo diáspora traz profundas relações com a palavra deslocamento. Nessa perspectiva, é interessante anunciar o que Paul Gilroy escreve no seu livro Entre campos acerca da noção de diáspora:

Identifica uma rede relacional, produzida de modo característico pela dispersão forçada e pela saída às pressas e relutante. [...] Não é apenas uma palavra de movimento, embora o movimento desesperado e determinado seja integral a ela. (GILROY, 2007, p. 152)

Esse "movimento desesperado" (ou "dispersão forçada") foi determinado por movimentações inerentes a uma filosofia muito bem construída, com narrativa muito bem configurada: a colonialidade. Foi a chave que abriu a porta das travessias no Atlântico, alimentando o olhar dos primeiros europeus em relação aos territórios americanos e seus moradores. Maldonado-Torres (2007) considera que a colonialidade não é simplesmente consequência de uma "forma residual" de qualquer relação colonial, porque essa relação (à qual "colonialidade" se refere) nasce, especificamente, da invasão dos Ibéricos nas Américas.

A repressão e inferiorização dos corpos dos povos colonizados e subjugados foram os primeiros meios ideológicos para concretizar o projeto coIonial. Arquitetado por etapas continuadas, século a século, a ideia do corpo diferente para uma ideia de corpo racializado e heteronormativo foi construída paulatinamente, sob diversos aspectos. Desde críticas e repressões 
referentes ao movimento dos quadris nas comunidades africanas centrais, passando pela demonização da cultura antropofágica dos indígenas, até as limitações impostas ao uso do tato no próprio corpo dentro da sociedade europeia (PRECIADO, 2014). Essa imposição operada por meios cognitivos, psíquicos e sociais concretiza a superioridade biológica desenhada como natural. Como bem afirmou Lélia Gonzalez (1988, p. 72):

Quando se analisa a estratégia utilizada pelos países europeus em suas colônias, verifica-se que o racismo desempenhará um papel fundamental na internalização da "superioridade" do colonizador pelos colonizados.

Assim, é perceptível que a colonialidade tem no racismo um dos principais meios para renovar a desestabilização e o desmonte de narrativas corporais não eurocêntricas-brancas. Mas as populações negras nas Américas realocam suas estruturas simbólicas e investigam espaços de respiro para que possam mudar do lugar onde foram colocadas pelo colonizador. Nesse sentido, a reapropriação do corpo, através do movimento e dos encontros coletivos que cultivam situações artísticas culturais, é um valioso caminho para estudo. Ao trazer o exemplo das relações entre a família de Araci Cortes e Pixinguinha, identifica-se a rede relacional sinalizada por Gilroy, aqui considerada como uma espécie de invólucro presente durante e após o processo de escravização. Invólucro - que não significa falta de contato ou participação nos mundos branco-colonizador e indígenas - é um envoltório onde teias são criadas pelas(os) e entre artistas negras(os) que, pelas frestas de uma sociedade construída via tragédia colonial, se protegem e se retroalimentam.

Nas citações de Ruiz (1984), um dos biógrafos de Araci Cortes, aparece os nomes de China e Henrique. Eles eram os irmãos mais velhos de Pixinguinha. Em 1921, Araci e Pixinguinha trabalharam juntos no grupo Os Oitos Batutas. Esta banda de choro e jazz, formada por homens, viajou por algumas cidades do Brasil, como São Paulo, Santos, Ribeirão Preto, Juiz de Fora, Belo Horizonte, Recife e Salvador. Cortes foi convidada por China para integrar o grupo na época em que este apresentava, também, algumas peças de revista escritas por Mário Magalhães. Araci Cortes, nesse invólucro diaspórico, defendido aqui como elemento constituinte na experiência do deslocamento de muitas(os) artistas negras(os), inicia uma carreira significativa no 
Teatro de Revista a partir da experiência nos Oito Batutas. Sua entrada nesse grupo foi mediada por China:

Desde pequenina que dançava e cantava no colégio onde era a primeira... na faceirice e respeitada no samba.

Depois, fiz-me amadora do palco na sociedade "Filhos de Talma". Sentindo vocação para a cena, trabalhei no Democrata Circo dirigido por Benjamin de Oliveira. Daí, incorporei-me aos 8 batutas e fiz minha estreia no Teatro Lírico

...Há alguns anos passados, o esplêndido conjunto de artistas nossos, a frente estavam o "China" e o Pixinguinha, mais seis outros companheiros, formando o grupo musical dos 8 batutas, depois de retumbante sucesso sozinhos se lembravam de dar uma nova modalidade ao seu trabalho, intervindo na representação de pequenas peças teatrais.

Nosso confrade Mário Magalhães, então cronista de A Noite, com o intuito de auxiliá-los, escreveu uma pequena burleta intitulada "Um batismo na Favela", em que estava uma mulata dengosa do célebre morro.

- Quem há de fazer o papel da mulata? - perguntou o autor.

E o "china" lembrou:

- A Zilda Espíndola, que é uma pequena de muita habilidade para isso. (ARACI..., 1931, p. 28-29)

A artista ficou pouco tempo no grupo e logo em seguida foi trabalhar com atores-empresários como Jardel Jércolis e Genésio Arruda, além de encontrar o jornalista José do Patrocínio Filho (conhecido pelo apelido de Zeca), filho do abolicionista negro José do Patrocínio.

Assim, ao encontrar algumas pesquisas e fontes a respeito de alguns artistas negros do início do século XX, podemos verificar um invólucro simbólico que aponta para um possível contraprojeto colonial, em que, de forma peculiar, artistas se encontram e se nutrem de forma cadenciada, sincopada, macia e sorrateira, mantendo-se presentes na cena artística.

As populações indígenas e negras caminham e sofisticam seus recursos contra as atitudes imperiais de diversas maneiras. Isso proporciona movimento contínuo de retorno a seus lugares como sujeitos das próprias narrativas e valores. Por isso, considera-se o invólucro simbólico frequentado por Araci Cortes, Pixinguinha, José do Patrocínio Filho, China, Henrique, Grande Otelo, Dalva Spíndola, como uma prática decolonial ou descolonial. Como aponta 
Mignolo (2008, p. 291): "Na América do Sul e na América Central, o pensamento descolonial vive nas mentes e corpos de indígenas bem como nas de afrodescendentes"' É vontade de existir que pulsa e que se requalifica, seja de forma ambígua ou não, seja de forma irônica ou não.

Assim como o invólucro simbólico narrado anteriormente, existiram muitos outros exemplos. Um que podemos suscitar aqui é a partir das poucas fontes que se tem a respeito da atriz Ascendina Santos, que trabalhou na Companhia Carioca de Burletas, repercutindo significativamente na crônica e imprensa do período de 1926:

No dia seguinte à première (o francesismo era moda na época) da burleta carnavalesca Ai, Zizinha!, que verificou-se a 15 de janeiro de 1926, no teatro Carlos Gomes, o crítico do venerando matutino carioca registrou sobriamente a ocorrência. Sintetizando sua assinatura com a inicial L. disse: [...] "o êxito sensacional da noite e os melhores aplausos couberam à Sra. Ascendina dos Santos, dama de cor que fez ontem sua estreia." $\mathrm{Na}$ mesma data, sem ademanes literários, outro crítico, Mário Nunes, registrava: "a peça apresentou a maior novidade de 1926 - Ascendina Santos, artista negra como azeviche, que canta, dança e representa de maneira que obteve fartos e calorosos aplausos da plateia". (EFEGÊ, 2007, p. 59)

Em abril de 1926, a artista Rosa Negra atuou na peça Pirão de Areia, a qual tinha um quadro denominado Ascendices, uma espécie de referência que Rosa e um grupo de Black-Girls fazia a Ascendina dos Santos. Rosa Negra, por sua vez, foi a grande vedete da primeira fase da Companhia Negra de Revistas idealizada por D'Chocolat, grupo que aglutinou e revelou muitas(os) artistas negras(os) em 1926, ano do seu surgimento (BARROS, 2005). Para Gomes (2004) A Cia Negra seria um surgimento singular naquele período. O discurso do grupo, representado pela sua própria denominação, contrariava e tencionava, naquele momento, o discurso da mestiçagem e da harmonia racial veiculados por certos intelectuais como Gilberto Freyre. Para Gomes, a Companhia Negra de Revistas representava de certa forma o que os afrodescendentes pensavam sobre o tema identidade nacional. É interessante ressaltar que tanto Barros (2005) quanto Gomes (2004) trazem informações documentais referentes a comentários preconceituosos por parte da imprensa do período em relação à Companhia Negra de Revistas. 
Após o rompimento entre o artista-empresário D'Chocolat e o cenógrafo Jaime Silva, fundadores da Companhia Negra de Revistas, ainda em 1926, é criada a Ba-Ta-Clan-Preta por Déo Costa, a Vênus de Jambo e D'Chocolat. O interessante é que, de 1926 a 1927, tanto pela Companhia Negra de Revistas, quanto pela Ba-Ta-Clan-Preta, transitaram muitas(os) artistas negras(os), eis aqui alguns nomes: Dalva Spíndola (irmã de Araci Cortes), Pixinguinha, Grande Otelo, Rosa Negra, Domingos de Souza (Mingote), a bailarina Imperalina Dugann, Guilherme Flores e Oswaldo Vianna (BARROS, 2005).

\section{Por enquanto, algumas considerações}

Esse panorama, no qual artistas negros transitam o tempo todo, ao mesmo tempo que se entrelaçam uns nos outros, aponta para uma forma específica de ocupação de artistas afro-brasileiros no cenário artístico. É possível identificar deslocamentos nos ambientes artísticos que em certa medida se interligam à vida cotidiana desses mesmos artistas e seus encontros, como sambas e rodas de choro. É como se o pulsar da dança, do canto e da dramaticidade que acontece nos palcos fosse a extensão da vida diária, apresentando outra lógica de entendimento de aprender arte. Nesses deslocamentos se percebe o invólucro, o retorno a si configurado em conexões sutis desses artistas uns com os outros, mesmo no circuito branco. Ao voltar os olhos para o contexto contemporâneo, veremos que a situação não é muito distante, já que políticas culturais periféricas têm se fortalecido cada vez mais por conta das relações entre artistas e coletivos negros, seja no campo da dança, do teatro, da música ou das artes visuais. Sendo assim, não seria demasiado retornamos para os invólucros de artistas negras e negros do passado que, num contexto pós-abolição, formaram criativamente suas teias, para que reinventemos estratégias cada vez mais sofisticadas de aperfeiçoamento das nossas redes.

Como disse Fanon (2008, p. 28):

A sociedade, ao contrário dos processos bioquímicos, não escapa à influência humana. É pelo homem que a sociedade chega ao ser. O prognóstico está nas mãos daqueles que quiserem sacudir as raízes contaminadas do edifício. 
A colonialidade tem uma direção muito consciente de suas escolhas e opções, uma dramaturgia com ações muito bem estruturadas, uma coreografia demasiadamente pesquisada, ciente dos seus improvisos e dos intérpretes que nutrem esse projeto, sob diversas maneiras e configurações. Precisamos sacudir essa proposta, cuja historiografia é balizada em uma verdade única. Necessitamos "modificar as posições de enunciação" (PRECIADO, 2014, p. 27) para que nossas redes sejam cada vez mais invólucros e territórios decoloniais.

\section{Referências bibliográficas}

ARACI Cortes e seus sambas. O Cruzeiro, Rio de Janeiro, 22 ago. 1931, p. 28-29.

BALLESTRIN, L. América Latina e o giro decolonial. Revista Brasileira de Ciência

Política, n. 11, p. 89-117, 2013. Disponível em: <http://bit.ly/2tO9Qb3>. Acesso em: 21 jul. 2017.

BARROS, O. Corações de Chocolat. A história da Companhia Negra de Revistas (1926-27). Rio de Janeiro: Livre Expressão, 2005.

BRITO, D. S. Um ator de fronteira: uma análise da trajetória do ator Grande Otelo no teatro de revista brasileiro entre as décadas de 20 e 40. 2011. Dissertação (Mestrado em Artes Cênicas) - Programa de Pós-Graduação em Artes Cênicas da Escola de Comunicação e Artes, Universidade de São Paulo, São Paulo, 2011. EFEGÊ, J. Meninos, eu vi. Rio de Janeiro: Funarte, 2007

FANON, F. Pele negra, máscaras brancas. Tradução de Renato da Silveira. Salvador: Edufba, 2008.

GILROY, P. Entre campos: nações, culturas e o fascínio da raça. São Paulo: Annablume, 2007.

GOMES, T. M. Um espelho no palco: identidades sociais e massificação da cultura no teatro de revista dos anos 1920. Campinas: Unicamp, 2004.

GONZALEZ, L. A categoria político-cultural de amefricanidade. Tempo Brasileiro, Rio de Janeiro, n. 92-93, p. 69-82, 1988.

MALDONADO-TORRES, N. Sobre la colonialidad del ser: contribuciones al desarrollo de un concepto. In: CASTRO-GÓMEZ, S.; GROSFOGUEL, R. (ed.). El giro decolonial: reflexiones para una diversidad epistémico más allá del capitalismo global. Bogotá: Siglo del Hombre, 2007. p. 127-168. Disponível em: <https://goo.gl/ hHc2Ge>. Acesso em: 2 mar. 2016.

MIGNOLO, W. Desobediência epistêmica: a opção descolonial e o significado de identidade em política. Cadernos de Letras da UFF - Dossiê: Literatura, língua 
e Identidade, Niterói, n. 34, p. 287-324, 2008. Disponível em: <https://goo.gl/ ZfGyUE>. Acesso em: 15 mar. 2016.

PRECIADO, B. Manifesto contrassexual: práticas subversivas de identidade sexual. São Paulo: N-1 edições, 2014.

RUIZ, R. Linda flor. Rio de Janeiro: Funarte, 1984.

Recebido em 23/04/2017

Aprovado em 06/06/2017

Publicado em 05/09/2017 